Revista Iberoamericana. Vol. LXIV, Núms. 184-185, Julio-Diciembre 1998; 611-626

\title{
ALFREDO BRYCE ECHENIQUE EN EL FIN DE SIGLO
}

\author{
POR \\ ISABEL GALLEGo \\ Junta de Educación, Andalucía (España)
}

Alfredo Bryce Echenique (Lima, 1939) ocupa un lugar destacado en la narrativa del último cuarto de siglo desde que en el año 1972 ganara el Premio Nacional de Literatura del Perú por su novela Un mundo para Julius (1970). El éxito de 1972 se corroboró veinticinco años más tarde cuando noventa y tres personas representativas del mundo literario y cultural peruano, en una encuesta realizada por la revista peruana Debate ("Las diez mejores novelas peruanas"), eligió Un mundo para Julius entre las diez mejores novelas peruanas. En realidad, fue la novela más votada, seguida de El mundo es ancho y ajeno (1941) de Ciro Alegría, Los ríos profundos (1958) de José María Arguedas y Conversación en la catedral (1969) de Mario Vargas Llosa.

A Un mundo para Julius le siguieron una serie de novelas que se pueden estructurar en torno a los ejes geográficos en que se desarrollan, el Perú y Europa, sobre cuyos ejes se organizan las novelas que nombro como ciclo peruano y ciclo europeo respectivamente. Un mundo para Julius y No me esperen en abril (1995), novelas del ciclo peruano, recogen el testimonio nostálgico de la vida de la alta burguesía limeña durante las décadas de los 50 y 60. ${ }^{1}$ Tantas veces Pedro (1977), La vida exagerada de Martín Romaña (1981), El hombre que hablaba de Octavia de Cádiz (1985) y Reo de nocturnidad (1997), novelas del ciclo europeo, narran la biografía de unos personajes limeños residentes en Europa en las décadas de los años 60, 70, y 80. La última mudanza de Felipe Carrillo (1988) es una novela puente que abarca ambos ejes geográficos pues se desarrolla en Europa y en el Perú.

En estas novelas se presentan dos actitudes definitorias del fin de siglo: la nostalgia y la autorreflexión. Nostalgia y autorreflexión, actitudes atávicas en la literatura, adquieren unos contornos especiales en este fin de milenio, dada la transformación radical que ha sufrido la sociedad y la forma en que el individuo se identifica dentro de la misma. Actualmente nos encontramos inmersos en un mundo que ha visto unos cambios profundos en la concepción de la sociedad y de las relaciones que en ésta se establecen. ${ }^{2}$ Estos cambios han venido propiciados principalmente por los avances de la ciencia. Los descubrimientos de los últimos siglos, que se han acelerado a un ritmo desconocido durante las últimas

\footnotetext{
${ }^{1}$ Aunque No me esperen en abril abarca cronológicamente desde 1952 hasta 1995 son las décadas de los años 50 y 60 las que se recuerdan nostálgicamente.

2 Algunas de estas ideas se han gestado en las lecturas del sociólogo Anthony Giddens.
} 
décadas, han provocado que asistamos y participemos en un festín vital que habría sido considerado un atentado a la razón y a la naturaleza tan sólo cincuenta años atrás.

Los inventos de la ciencia, que comenzaron a tener un ritmo trepidante desde la Revolución industrial, han contribuido a separar el tiempo del espacio y del lugar. Esta separación es uno de los factores determinantes en los cambios sociales y en los nuevos conceptos de relaciones sociales que se establecen como resultante de estos cambios. Lo espacial, que se caracteriza por abarcar múltiples y distantes realidades, ha adquirido un papel preponderante en detrimento de lo local. Esto ha operado como fuente de desequilibrio en el individuo, que busca ajustarse a un orden en el que la geografía concreta y las relaciones sociales que en ésta se establecían ya no son la base de la identidad. El animal social del que hablaba Aristóteles, era social en cuanto a que pertenecía a una localidad circunscrita a una geografía concreta, en la que el hombre tenía una autonomía que se afianzaba en el marco de una sociedad tradicional.

Personas como Bryce Echenique, que no es una excepción en nuestros días, han organizado su espacio vital en geografías múltiples. El escritor, nacido en Lima en 1939, se establece en Europa desde 1964. Sus lazos emocionales y vivenciales se expanden en el Perú, Francia y España principalmente, con ramificaciones en otros países en los que ha vivido temporalmente o en los que se encuentran personas con las que ha compartido experiencias de importancia. Hablamos, pues, en cierto sentido de la globalización del espacio en que se habita y de las relaciones sociales que en este espacio global se establecen. Esta globalización ha provocado un desanclaje de las relaciones sociales de sus contextos locales de interacción por lo que éstas se han reestructurado en indefinidos espacios temporales (Giddens, Consecuencias 32).

Viene a nuestro pensamiento la asociación entre Bryce Echenique y la literatura del exilio. La utilización del término "exilio" en nuestros días conlleva una complejidad de significaciones que lo puede convertir en un término inoperante e inválido para nombrar los múltiples y diferentes tipos de exilio que existen en la actualidad. En momentos de la historia en los que la norma era habitar en el lugar de nacimiento, o cuando más, trasladarse dentro de las propias fronteras del país en el que cada uno había nacido, el exiliado era una excepción. A esta situación anómala y excepcional se llegaba principalmente por razones económicas o políticas. Lo que se conoce bajo el nombre de exilio cultural es un fenómeno más reciente y propio de la modernidad. ${ }^{3}$ Todas estas distinciones, y la misma necesidad de acuñación de la palabra "exilio" no hacían más que denotar que el hecho de "irse fuera de" era una anomalía. ¿Podríamos decir ahora lo mismo cuando el desplazamiento es un lugar común en esta época? ¿Se podría llamar exiliadas a las múltiples y variadas comunidades, o los más diversos individuos que viven en lugares diferentes a aquellos en donde nacieron y donde se educaron?

Lo característico del exilio, fuera del orden que fuera, era la dialéctica que se establecía entre presencia y ausencia. La presencia en un sitio implicaba la ausencia en el otro. Este juego de ausencias y presencias operaba como arquetipo motivador de la escritura. En la

\footnotetext{
${ }^{3}$ Se empleaba el nombre de exilio cultural para referirse al exilio voluntario que venía propiciado por el descontento del individuo en su país de origen, descontento que abarcaba el terreno de lo cultural y de lo social, principalmente.
} 
actualidad, la globalización ha hecho que "Presencia y ausencia se mezclen en formas históricamente inéditas" (Giddens, Consecuencias 165). Por lo tanto, ya no es necesario salirse de un lugar para sentirse ausente. El exilio, que no es otra cosa que el alejamiento de las estructuras sociales que dan seguridad a un individuo para funcionar como tal, ha pasado a ser metáfora de la situación de desconcierto y enajenación del hombre contemporáneo: "displacement and misplacement are a common place in this century" (Brodsky 2). Las palabras que Jean Baudrillard usa para describir la forma en la que los individuos se ven afectados en la actualidad por la invasión de las telecomunicaciones en la vida pública y privada podrían aplicarse a la forma en que el hombre se sentía en el exilio más tradicional:

Private 'telematics': each person sees himself at the control of a hypothetical machine, isolated in a position of perfect and remote sovereignty, at an infinite distance from his universe of origin. Which is to say, in the exact position of an astronaut in his capsule, in a state of weightlessness that necessitates a perpetual orbital flight and a speed sufficient to keep him from crashing back to his planet of origin (152).

Santiago, protagonista de la novela corta de Bryce Echenique "Los grandes hombres son así. Y también asá", es un joven peruano que vive en París. De su vuelta al Perú se recoge este fragmento en el que se observa su desconcierto:

-No sé. Me ha pasado algo, pero muy de lejos. Yo creo que este señor te lo puede contar, porque a mí algo me ha estado contando, pero me suena todo tan lejano. Tal vez un buen pisco y un billete de regreso a París ... ¿Tú sabes bien donde estoy? ¿Tú sabes bien quién eres?

-Santiago, soy Raúl. Raúl tu amigo, Raúl tu hermano ...

-Que este señor te cuente. Yo me siento ausente y lejano ya para siempre (250-51).

Este tipo de sensaciones no existía cuando el individuo se integraba en un espacio comunitario que estaba inmerso en una tradición. La tradición era una manera de integrar la consciencia de nosotros mismos y la relación con el mundo en la organización del tiempo y del espacio de la comunidad. La tradición contribuía de manera fundamental a la seguridad ontológica en tanto que sostenía la confianza en la continuidad del pasado, presente y futuro, y conectaba esa confianza con las prácticas sociales rutinarias (Giddens, Consecuencias 45). El presente con sus marcados cambios sociales, promovidos por los cambios radicales en cuanto a la valoración del tiempo y del espacio, rompe la conexión con el pasado. El hombre se siente como en una cápsula orbitando en nuevos círculos, desde los cuales se puede recordar un mundo más estable, si es que se ha vivido, pero indudablemente el recuerdo va unido a un sentimiento absoluto de pérdida.

La preponderancia que adquiere un espacio más abstracto en el que caben a un mismo tiempo varios espacios y varios tiempos, trae consigo cierto desequilibrio que se manifiesta en un fuerte sentimiento de nostalgia hacia un pasado en el que se vivía en un espacio más estable y menos confuso porque estaba afianzado en la tradición. El desconcierto del presente puede inducir a recrear el pasado de forma nostálgica. Sin embargo la nostalgia, que requiere de la memoria para que se realice, nos sitúa en unas coordenadas espaciales, 
en las que el pasado invade el espacio del presente y del futuro, por lo que no se soluciona el desconcierto del que se parte. Precisamente esta actitud nostálgica viene motivada, en opinión de Brodsky, por la imposibilidad de enfrentarse a la realidad del presente o a las incertidumbres del futuro (5).

Hay pueblos, como el peruano, del que se dice que su propio nacimiento como nación está basado en un cambio tan brusco, como el que supuso la desaparición del Incanato, que la nostalgia de esos tiempos, que ha entrado a formar parte del mito del paraíso perdido, figura en la propia base de creación del moderno pueblo peruano. De ahí el componente nostálgico tan marcado del pueblo peruano que se manifiesta en la literatura, en la expresión plástica y en la música. Maximiliano Gutiérrez, protagonista de Reo de nocturnidad, dice: "No hay, ni puede haber nada ni nadie más nostálgico y con más bienes perdidos que un peruano" (Reo de nocturnidad 234).

La nostalgia es la característica de las novelas del ciclo peruano. Por medio de una incursión novelística en el pasado, Bryce Echenique recupera la vida en una sociedad tradicional. Pero nostalgia y fin de una tradición van ciertamente unidas. La propia etimología de "tradición" nos indica que es consustancial a la misma que se "entregue" de generación en generación. Este acto de entrega y herencia otorga unas bases de afianzamiento ontológico a los que la reciben, pues para ellos su presente y su futuro está arraigado en dicha tradición. Perdida ésta, sólo cabe la recuperación de la misma por medio de una literatura de fuerte carácter nostálgico, dado que produce dolor lo que se da por perdido y desaparecido para siempre.

Las novelas del ciclo peruano hacen un canto a la vida entendida como aquella afianzada en unos usos y costumbres tradicionales. Así lo expresa el autor en uno de los epígrafes de No me esperen en abril :

Cada amanecer iluminaba un mundo idéntico a su víspera. No estaba en discusión el sistema sino sólo la identidad de sus conductores. Confiadas estirpes entrecruzaban sus destinos, sin que a nadie se le ocurriera la posibilidad de un futuro no calculado, fuera de control, rebelde o vengativo, que interrumpiera una amable sucesión de décadas en las que sólo había cambiado el largo de los vestidos [...].

Los protagonistas de no No me esperen en abril viven en una sociedad basada en una tradición heredada de tiempos de la colonia. Esto les daba una identidad y una razón de ser en el presente y para el futuro:

[...] se sabían casi todos herederos de lo mismo que habían heredado sus padres y de lo mismo que heredarían sus hijos, verdaderas tradiciones Ricardo Palma. Formaban parte, en el fondo, de la llamada generación puente, desde el virreinato hasta el fin del mundo [...] (No me esperen 288).

Domina en la novela la tristeza por el drama de la desubicación vital en la que viven unos personajes que van perdiendo privilegios y que ven desaparecer los pilares en los que se basaba su vida tradicional. El gobierno del general Velasco (1968-1975) supuso uno de los más fuertes golpes contra la oligarquía limeña, no sólo por las reformas sociales que 
promovió, sino también porque un mestizo, al que apodaban el "Chino" o el "Cholo", pudiera ocupar el poder.

Este sentimiento de pérdida no es algo que sólo Bryce Echenique haya experimentado, pues, en realidad, es una reacción ante los drásticos cambios de los que ha sido protagonista la ciudad de Lima y el Perú. Desde la últimas décadas Lima ha experimentado unos cambios profundos en su composición social, política y económica. Hasta comienzos del siglo XX la población campesina vivía en áreas rurales. Lima, por su parte, era todavía la antigua capital que había albergado las instituciones del virreinato y era uno de los mayores enclaves de asentamiento de la población criolla. A partir de 1895, el censo de la capital comienza a incrementarse notablemente. La comparación entre el censo de 1908 y el de 1920 indica que el crecimiento total de habitantes fue del $33 \%$.

Comienza a partir de entonces un desaforado aumento demográfico en Lima y un cambio total en la composición social de la ciudad, con el advenimiento de las masas campesinas expulsadas de sus tierras por malas condiciones o bajo la esperanza de mejores niveles de vida. Se inicia el proceso al que se alude con el nombre de "peruanización de Lima", caracterizado por el aumento de la población campesina en centros urbanos. En el año 1940 el Perú albergaba a 6 millones de habitantes de los cuales el 65\% vivía en áreas rurales. En 1990 el Perú alberga más de 24 millones de habitantes de los cuales el $70 \%$ habita en ciudades, contando actualmente la ciudad de Lima con más de siete millones de habitantes (Doering 293).

La proliferación de libros y artículos sobre la nueva Lima es índice de la importancia de los cambios ocurridos y del interés que suscita. ${ }^{4}$ Cornejo-Polar afirma que "la emigración del campo a la ciudad es el hecho de más incisiva y abarcadora trascendencia en la historia moderna del área andina" (837). Añade Cornejo-Polar que "la identidad de la ciudad ha variado de forma sustancial y la relación de pertenencia del personaje entra en crisis hasta convertirlo en un visitante precario de una ciudad que fue suya y está dejando de serlo" (837). Así lo constata Bryce Echenique en su autobiografía:

Que a Garcilaso de la Vega Chimpu Ocllo y a Bryce Echenique les serruchó el piso la historia hasta hacerlo desaparecer bajo sus pies, qué duda cabe. Al Inca se le acabaron el Imperio Incaico y la estirpe de los conquistadores como su padre. Y a mí se me acabó la Lima de Chabuca Granda y La flor de la canela, llamada también Lima la horrible, por otro ilustre limeño, Sebastián Salazar Bondy, y esto no es poca cosa. Salí de una Lima en que nunca pude aprender el quechua en ninguna parte y hoy vuelvo a una Lima que es la primera ciudad quechuahablante del país (Permiso 21-22).

Alfredo Bryce Echenique se ha vuelto el cronista de una época que ha desaparecido. Los cambios son mucho más dramáticos que los que constataban los escritores costumbristas de finales del siglo XIX. Ricardo Dávalos y Lisson (1852?-1877) se lamentaba de que estuvieran desapareciendo las tapadas, o que se prefiriera el roastbeef a los bizcochos típicos limeños (Lima de antaño 86). José Gálvez (1885-1957), representante de una corriente

\footnotetext{
${ }^{4}$ Hay numerosa bibliografía sobre este tema. Son importantes los trabajos de Aníbal Quijano, María Méndez Gastelumendi y José Guillermo Nugent. En el campo estrictamente literario, Peter Elmore ha realizado un trabajo sobre la modernización de Lima y su repercusión en la literatura.
} 
neocostumbrista de principios de siglo, aunque lamentaba la desaparición de las costumbres y usos pintorescos de la Lima tradicional, sentía cierto optimismo hacia el futuro que abría la modernidad: "Y aunque deja una impresión de suave melancolía esta mutación tan honda, no debemos negar que hemos ganado y que parece que nos hemos incorporado ya sin vacilaciones al movimiento de la vida universal" (Una Lima que se va 261).

Parte del éxito de Bryce Echenique radica en que su obra representa el pasado que ya ha dejado de tener vigencia, por lo que se convierte en el cronista sentimental de una época:

Yo represento el pasado para esos entrañables seres que son el pasado. Un pasado que se abre paso serenamente a balazo limpio, si es necesario, entre los nuevos limeños. Yo represento esa Lima que olía a Yardley mejor que la Comunidad Europea y por donde hoy circulan suicidamente unos informales microbuses que vienen de barrios que no conozco y van hacia barrios que ya jamás conoceré. Y así es, mi querido Inca Garcilaso, el serrucho de la historia no huele a Yardley sino que huele como mierda. Pero esto es lo que se llama la peruanización del Perú y a tí te pescó en el siglo XVII y a mí en el XX (Permiso 23).

Es interesante ver la diferencia entre el realismo de los autores de La Generación del 50 y el de Bryce Echenique. ${ }^{5}$ De ellos le separan la visión de fin de la tradición y fin de la historia de Lima tradicional. Los escritores del 50 son más combativos y más comprometidos socialmente que Bryce Echenique. En sus cuentos y novelas no lloran la pérdida del pasado sino que critican la situación del presente. Toda crítica lleva implícita la esperanza de cambio. Por el contrario, en las novelas del ciclo peruano hay una sensación de derrota total.

Los miembros de la Generación del 50, que comenzaron lo que se llamó narrativa urbana, dejaron constancia de las transformaciones de la ciudad de Lima hacia la mitad del siglo. Una ciudad que en su composición sociológica reflejaba el cambio de una sociedad campesina, no tanto a una sociedad industrial, sino a una sociedad en que una gran parte del campesinado, depauperado, entraba a formar parte de la población limeña. Por otra parte, se reflejaba con pesimismo la situación de la clase media limeña, que se caracterizaba por su poco optimista visión del futuro. Julio Ramón Ribeyro en La Generación del ' 50 expresa su interés en escribir sobre la Lima en transformación, sin sentir nostalgia en absoluto por la Lima que estaba quedando suplantada: "La Lima que yo quería escribir era una Lima en transformación" (192). Deseaba así mismo dotarles de voz a los seres marginales que hasta entonces no habían encontrado un lugar en la novelística, de ahí el título de su colección de cuentos La palabra del mudo (1973).

Porque en la mayoría de mis cuentos se expresan aquellos que en la vida están privados de la palabra, los marginados, los olvidados, los condenados a una existencia sin sintonía

\footnotetext{
${ }^{5}$ A pesar de las diferencias, Alfredo Bryce Echenique reconoce la deuda que los escritores de su generación tienen con los escritores de la Generación del 50: "los 4 ó 5 novelistas peruanos actuales de renombre internacional les debemos muchísimo al sacrificio que tuvieron que pagar los de la generación de los años 50 , por tratar de ser diferentes en una sociedad que intentó eternizarse, y en la que había escritores como Sebastián Salazar Bondy, como Heliodoro Vargas Vicuña, como el propio Julio Ramón Ribeyro" ("La Generación del 50”, 53).
} 
y sin voz. Yo les he restituido este hálito negado y les he permitido modular sus anhelos, sus arrebatos y sus angustias. ${ }^{6}$

Estos autores hacían una literatura de denuncia y por lo tanto, aunque pesimistas ante la situación del presente, tenían esperanzas en la consecución de una sociedad más justa.

Bryce Echenique no tiene como principal fin criticar a la alta burguesía limeña de los años 50 y 60 , sino dar un testimonio de su existencia, y recuperarla a través de un sentimentalismo nostálgico en el que no da lugar al resentimiento. El niño Julius ve con dolor cómo el mundo de su niñez, el mundo de la oligarquía, desaparece y se va insertando un nuevo mundo, tanto el que representa una burguesía tecnócrata como el que representan las masas de campesinos que comienzan a instalarse en la ciudad de Lima. Igualmente No me esperen en abril es un canto homenaje a aquellas personas que se sentían seguras porque pertenecían a una clase y a una tradición que sus hijos estaban destinados a perpetuar. Las obras del ciclo peruano son puro territorio de la nostalgia y, en verdad, el último testimonio novelístico importante de la oligarquía limeña de los años 40 y 50 (Lerer, Gutiérrez). Solamente un escritor como Bryce Echenique, nacido en el seno de esa clase, podría reflejarla con absoluto conocimiento y viveza.

Los protagonistas de las novelas del ciclo europeo son exponentes de otra de las características de este fin de siglo: la preponderancia de un yo autorreflexivo. El desconcierto del individuo del fin de siglo provoca un marcado narcisismo narrativo, que compensa la desaparición de unas estructuras sociales tradicionales. A la desaparición de las mismas, que se constataba en la novelas del ciclo peruano, se une ahora una suerte de situación de doble exilio (o marginalidad doble como la llama Bryce Echenique) pues los personajes se encuentran en una sociedad y en una geografía nueva para ellos. La construcción del yo como un proceso reflexivo es consecuencia de la pérdida de seguridad ontológica que antes aportaba el estar inserto en una tradición social viva y vigente.

Si en las sociedades tradicionales, un hombre se podía definir por su pertenencia a una familia, una ciudad y unas tradiciones vigentes que le conferían la seguridad necesaria para el afianzamiento de su identidad (Weintraub 2-3), el hombre alejado de las estructuras sociales tradicionales en las que nació —o bien porque éstas hayan sufrido unos cambios radicales o bien porque se haya alejado geográficamente de ellas, o bien por las dos cosas, como es el caso de Bryce Echenique-, debe encontrar otros parámetros para colmar el deseo de pertenencia necesario para la construcción de la identidad. Es el individuo quien a través de un proceso de autorreflexión tiene que encontrar las certidumbres que la tradición aportaba. El alejamiento del lugar de origen y la falta de tradiciones que le vengan dadas trae consigo que adquiera mayor relevancia en el individuo lo que el sociólogo Anthony Giddens denomina "disposiciones personales" (Modernity and Self-Identity 2), que remiten al terreno de la capacidad de reflexividad del individuo.

$\mathrm{Si}$ atendemos a las novelas que han tratado sobre la vida de los latinoamericanos en Europa, como hacen las novelas de Bryce Echenique, veremos cómo la importancia que a principios de siglo tenía lo social ha dado paso a unas novelas mucho más concentradas en

\footnotetext{
${ }^{6}$ La cita proviene de una carta escrita por Julio Ramón Ribeyro al editor Carlos Milla Batres, la cual esta fechada el día 15 de febrero de 1973.
} 
la conciencia individual. A comienzo de siglo se creía que los problemas de identidad eran principalmente la consecuencia de la inserción en una sociedad ajena. Estos problemas se resolvían principalmente mediante una aceptación de la tradición en la que cada uno había nacido, y a la que por lo tanto se pertenecía. Los intentos de negar esta verdad tenían como resultado la muerte espiritual, moral o física de los personajes. En una época en la que se ha institucionalizado la duda y el escepticismo estos planteamientos nos parecen ingenuos y poco convincentes.

Así Eugenio Cambaceres (Buenos Aires 1843 - París 1888) en Música sentimental (Silbidos de un vago) (1884) parte de una tesis de que París es un lugar que provoca la enfermedad moral. Lo ejemplifica con la ruina física y espiritual del joven latinoamericano Pablo Larmont.

A esta novela le siguieron otras enfocadas así mismo en denigrar la capital francesa y en censurar la influencia negativa que ejercía sobre los latinoamericanos deseosos de integrarse en ella. En estas novelas los personajes presentan raros atisbos de individualidad. Era más importante resaltar el lado social y constatar la imposibilidad de adaptación de los latinoamericanos en una tradición distinta a la de ellos. Los planteamientos y las respuestas novelísticas eran tajantes a la hora de ofrecer una fórmula de felicidad. Estamos lejos todavía del escepticismo, la duda y la desconfianza en fórmulas de felicidad generales y universales que caracteriza nuestra época.

Así pasa en la novela Rastaquouère 7 (1890) de Alberto del Solar (1860-1921), escritor chileno afincado en Buenos Aires, que defiende una sociedad que debe procurar la unión con personas del mismo origen nacional, de clase y de cultura. La mezcla de culturas, una realidad de nuestra época, es la causante de la infelicidad de los latinoamericanos que van a París, que en su afán de integración establecen relaciones con personas "extranjeras" (el "extranjero" se define todavía como el que no comparte nacionalidad). Los problemas se resuelven con optimismo según la fórmula de felicidad que da la novela: la vuelta "al hogar", a su lugar de origen donde familia, sociedad y tradición, a la par que el amor hacia su propia tierra, colman de significado su vida.

Es la misma tesis que ofrece Alberto Blest Gana (Santiago 1830 - París? 1920) en Los transplantados (1904). Visiones contrastivas y maniqueas, similares a las novelas anteriores, presenta Criollos en Paris (1939) del novelista chileno Joaquín Edwards Bello (1888-1968). Ricardo Güiraldes (1886-1927), comparte con los anteriores su fe en la redención del exiliado en tierras americanas aunque dota al medio natural americano de una espiritualidad desconocida hasta el momento en la narrativa. Si Música sentimental reflejaba la perdición de su protagonista en un París de tintes naturalistas que llevaban al

\footnotetext{
${ }^{7}$ Según descripción de Alberto del Solar "el americano del sud, ya fuese argentino, chileno, boliviano, venezolano o colombiano, quedaba convertido, a la vista de los europeos, en el 'verdadero, el único rastaquouère; el rastaquouère por excelencia'; personaje ridículo, absurdo, a quien se pintaba con rasgos por el estilo de los siguientes: tipo de color moreno subido, facha estrafalaria, vestir aparatoso y grotesco, talante finchado, andar de pavoneo,--especie de crisólito viviente, por lo chillón de su atavío y por el brillo de los diamantes de que se le suponía cubierto, desde la cabeza hasta los piesespecie de bolsa llena de oro, desgarrada por una punta, según era la cantidad de escudos que se aseguraba iba derramando a su paso y por doquiera [...]" (VII-VIII).
} 
protagonista a la muerte en un viaje sin retorno, en Raucho (1917) el protagonista regresa redimido a la Argentina para reposar en los brazos de la madre tierra.

Todas estas novelas ejemplificaban los valores tradicionales todavía no desaparecidos o en vías de extinción en el panorama social: la familia y la tierra. Además presentaban una visión negativa de lo cosmopolita. No es casual que buscasen fórmulas de enraizamiento en la tradición autores como Ricardo Güiraldes y como todos los anteriores, que habiendo vivido o sido educados en Europa, presentan una relación conflictiva con el país de origen y con el país de recepción. Se ve todavía como posible, y por lo tanto, está vivo el mito de la vuelta al hogar. Pues existe un hogar, ubicado además en terreno patrio. Este hogar/ patria/madre tierra es el representante de valores sociales y familiares sobre los que se asienta la identidad de los individuos. Esta visión parece ingenua para los lectores del mundo de hoy, que viven la emigración, el traslado, el exilio, cualquiera que sea el término que se le quiera dar, no como una anomalía sino como un hecho cotidiano. Y saben que el "mito de la tierra madre" o "el mito de la tierra prometida", es un mito que como tal no tiene visos de veracidad en la vida real de los hombres escépticos de fin de siglo.

La novela y el mundo que refleja van adquiriendo mayor complejidad. Los problemas del exilio comienzan a verse desde una perspectiva más amplia, y por ello ya no se resuelven en términos de identidad nacional. El problema se centra ahora en la soledad y el desconcierto individual a despecho de la geografia. Esta soledad se resuelve novelísticamente por medio de una mayor indagación en el individuo, que ya no se proyecta en el medio como vía de solucionar sus problemas. Empieza a vislumbrarse que la solución radica en uno mismo. En este diálogo con uno mismo la ciudadanía pasa a segundo término.

Esto se refleja ya en el conde de Monfort, protagonista de la novela de Angel de Estrada (1872-1923) Redención (1906), precursora de la interiorización del mundo narrado que se generaliza a partir de la década de los treinta. Se concentra la narración en la interioridad del conde de Monfort y en su visión esteticista de la realidad. En esta novela el protagonista ya ha superado las barreras sociales; para demostrarlo se le presenta totalmente integrado en el ambiente parisino, aunque hastiado de una vida dedicada a lo estético y al placer, y cansado de las veleidades de la ciudad y de sus amistades. Los problemas que se plantean traspasan por lo tanto el ámbito de lo nacional y se vuelven más complejos. La salvación ya se busca en las esferas de la vida íntima y privada, y no en lo social. La salvación/ redención viene de manos del amor: solución personal para un problema -el descontento vital-que ya no es social sino privado. Juan de Monfort es también el primer protagonista de este tipo de novelas que es escritor, y que busca en la introspección y en el ejercicio literario una salida a su ennui y a sus contradicciones.

En Nocturno europeo (1935) de Eduardo Mallea (Bahía Blanca 1903-1982), el protagonista Adrián es también un ser ensimismado. Su aislamiento sólo se rompe con el arrebato estético, intenso pero perentorio. Palabras como "angustia", "depresión", "aislamiento", "hermetismo" pasan a ser claves en su prosa y en su visión del hombre latinoamericano en Europa. El viaje para el protagonista es ya una herida eterna, por cuanto que está en continuo movimiento físico para encontrar una respuesta que sólo puede hallar en su actitud interior ante sí mismo. 
Horacio Oliveira en Rayuela (1963) transciende la geografía a través de un personaje que intenta superar las dicotomías espaciales occidentales (Rayuela 307). La tierra prometida de Oliveira no se encuentra en un lugar concreto, sino que es más bien un estado de ánimo. Oliveira, viajero que está "siempre de ida" (449), se burla de los problemas históricos de la búsqueda del "ser argentino o esquimal" (141) y sospecha que el único tema importante es "el peso del sujeto en la noción del objeto" (141).

Por su parte Sebastián Salazar Bondy, que hacía de la nostalgia de la Arcadia virreinal la protagonista de Lima, la horrible (1964), en Pobre gente de París (1968), ${ }^{8}$ trata sobre la vida de los latinoamericanos en la Ciudad Luz. La parte más destacada de este libro son los fragmentos en los que se da voz al protagonista, Juan Navas, que hace hincapié en los vacíos interiores con independencia del lugar en el que se vive. La culpa recae en el individuo, no en la ciudad, por las ilusiones y engaños que el propio individuo se teje sobre sí mismo, y de los que acaba siendo víctima implacable.

Aunque el humor no les falta a las novelas del ciclo europeo de Bryce Echenique, ${ }^{9}$ detrás de este humor se oculta el drama de unos individuos que buscan afianzar su identidad en el confuso mundo de finales de siglo. Desanclados de la tradición en la que nacieron e inmersos en unas nuevas coordenadas sociales y culturales, se concentran en sí mismos por la vía de la autorreflexión para asentar su identidad. Se alejan de intentar integrarse en el mundo social y buscan su realización personal en la esfera de lo privado. No es casual que La vida exagerada de Martín Romaña, El hombre que hablaba de Octavia de Cádiz y Reo de nocturnidad sean novelas narradas en primera persona. Son novelas narcisistas en las que los narradores se afanan en el relato de su propia vida para encontrar respuestas eminentemente personales a sus dudas existenciales.

Martín Romañay Maximiliano Gutiérrezejemplifican la necesidad de la autorreflexión a través de la escritura de sus novelas autobiográficas, que responden, en el fondo, a la necesidad de reafirmación de la propia existencia. La obsesión con su propia persona aparece patente en aquellas secciones en las que Martín Romaña se convierte a nivel textual en el receptor del propio proceso reflexivo: "Mientes, Martín Romaña [...] sigue, sigue, Martín Romaña [...]" (76).

Estos personajes buscan una curación a sus neurosis existenciales por medio de la escritura autobiográfica. Esta empresa no tiene como resultado el afianzamiento de su identidad pues es imposible que un yo en estado convalesciente halle cura en su propio yo. Con esto sólo se consigue caer en un círculo vicioso que lleva a incrementar la neurosis en lugar de curarla:

Hay en la narrativa de Bryce una búsqueda de un estado de convalescencia, de una cura o reparación, que no sólo se manifiesta temáticamente en las continuas visitas a médicos y psiquiatras de los protagonistas bryceanos, sino que se convierte en una suerte de

\footnotetext{
${ }^{8}$ Este libro recibe el título de la canción que dice Pobre gente de París / no la pasa muy feliz ... /y aunque no se quiera creer/debe ser verdad [...].

${ }^{9}$ Lawrence McCarty ha escrito una tesis titulada The Use of Humor in Three Novels of Alfredo Bryce Echenique. El autor comenta Un mundo para Julius, La vida exagerada de Martín Romaña y La última mudanza de Felipe Carrillo, usando las teorías sobre ironía, sátira y parodia de Thomas Hobbes, Sigmund Freud, Arthur Koestler, Northrop Frye y Mary Clarke Randolph.
} 
ideología literaria. Escribir y leer, pero en especial, escribirse y leerse, es decir, estos actos en su versión autoreflexiva, se ven como la vía hacia una reintegración psíquica y física del protagonista bryceano - aunque, paradójicamente, esa reintegración queda siempre diferida, pues la autocontemplación narrativa está siempre condenada a la mise en abyme (González 209).

Este viaje circular del yo al yo se manifiesta en la forma en que Martín Romaña termina estableciendo una relación simbiótica con el sillón desde el que redacta su biografía: "Además, no se olviden, soy yo el que está sentado en un sillón Voltaire. Yo soy el hombre del sillón Voltaire" (La vida exagerada 86).

Maximiliano Gutiérrez, protagonista y narrador de Reo de nocturnidad, es un hombre con graves problemas de afianzamiento personal. Montpellier, ciudad a la que llega a impartir clases y con deseos de empezar una nueva vida en la que no existan graves crisis de identidad, se convierte en "el gran teatro de mi inmenso desconcierto y mi pequeño mundo". ${ }^{10}$ Su aturdimiento vital se ejemplifica de forma simbólica en el solaz que encuentra al pasarse las noches, solo y sin rumbo, en el transbordador que comunica dos lugares remotos de la Camarga. Su desasosiego mental se somatiza en un insomnio crónico que lo lleva a un hospital. Desde ahí, intenta, como lo hacía Martín Romaña, curarse de su mal mediante la redacción de su biografía.

La forma optimista en la que terminan las novelas de Martín Romaña y Reo de nocturnidad, no se debe a que el proceso autorreflexivo haya tenido éxito en sí mismo, sino al hecho de que existe una mujer, Octavia en el caso de Martín Romaña, y Claire en el caso de Maximiliano, que al estar a su lado ayudan a romper la autoconcentración enfermiza. En estas novelas la razón de ser se encuentra en el amor. Lo mismo podríamos decir de Pedro Balbuena, protagonista de Tantas veces Pedro, que vive todo el acontecer novelístico buscando a Sophie. Aunque no sepamos si en realidad existe o ha existido, la vida de Pedro encuentra su razón de ser en ella.

Con esto le da un giro sentimental Bryce Echenique a los problemas de desconcierto del individuo que se resuelven por la vía del amor. El escritor se pronuncia claramente sobre la importancia del sentimiento: "Salvo por lo de su abismo, siempre me ha importado un repepino Descartes y su cartesianísimo 'Pienso, luego existo'. Modestamente, a esa frase opongo otra que ha dominado toda mi humilde existencia: 'Siento, luego existo"' (Permiso 425). El realismo de corte sentimental que confiere a sus obras se engloba dentro de una de las tendencias más fructíferas dentro de la narrativa del post-boom ("Alfredo Bryce Echenique: Turno sentimental" 454), al lado de autores como Manuel Puig o Luis Rafael Sánchez."

Por su parte La última mudanza de Felipe Carrillo combina la nostalgia del Perú y la autorreflexión como elementos básicos. La nostalgia del Perú no era un sentimiento importante en las novelas del ciclo europeo. Sus protagonistas, que están volcados en buscar soluciones a sus crisis de identidad presente, no encuentran lugar para la nostalgia. Su situación presente en París o en Montpellier, ciudades a las que llegaban con ánimos de

\footnotetext{
${ }^{10}$ Frase que Maximiliano dice repetidamente en la novela.

"Véanse los trabajos de Aníbal González y de Margarita Krakusin sobre Alfredo Bryce Echenique y la novela sentimental.
} 
emprender una nueva vida, no resultaba compatible con un viaje nostálgico al pasado peruano, lo cual habría anulado indudablemente el proyecto de las novelas. Otra cosa ocurre, sin embargo en La última mudanza. Felipe Carrillo es un peruano que ha triunfado en París como arquitecto. Tras haber conseguido el éxito, cae víctima de las trampas de la nostalgia, que le hacen desear un retorno al Perú. Pero no es sólo la novela una historia de su retorno al Perú sino una continua autorreflexión sobre su condición de hombre exiliado, víctima consciente de la nostalgia. Así, llevado de esta trampa intenta una relación de amor con una peruana, Eusebia Lozanos Pinto, en el Perú. La historia sólo sirve para darse cuenta de la imposibilidad de retorno a un mundo al que no pertenece. Felipe Carrillo comprende que a lo único que en realidad se acerca siempre es a sí mismo, y sus reflexiones son en realidad la parte más importante e imprescindible de la novela.

\begin{abstract}
El tren de regreso a París y el tren de la música de fondo y de la enorme distancia. Regresaba sin regresar a ninguna parte, creo, y lo menos que puedo decir es que sentía clavada en mi rostro una amarga mueca de balance final, de hasta aquí llegamos y de aquí no pasó nada. Pensaba que todas las soledades son distintas y son iguales y el paisaje castellano corriendo junto a la ventana del tren me entraba por un ojo y me salía por el otro. Porque yo dale con pensar y pensar en aquel tren de la ausencia me voy (206-07).
\end{abstract}

La autobiografia Permiso para vivir presenta una sintomatología fin de siglo semejante a las novelas. César Hildebrandt critica el "narcisismo nostálgico" de las memorias de Bryce Echenique (52). No se da cuenta Hildebrandt que precisamente aquello que censura es lo más destacado de las memorias, y lo que también caracterizaba su obra de ficción. El ensimismamiento o hiperconcentración se acrecienta por no verse compensado por un universo estable fuera del propio yo. El narcisismo del escritor peruano es reflejo de la situación de soledad y desconcierto con respecto al mundo en las que se escriben.

La autorreflexión que caracterizaba las novelas del ciclo peruano es también la característica de esta obra. Ocurre, sin embargo, como en las novelas, que el drama profundo de la persona que se va esbozando en el libro, puede quedar velado por el humor y por las anécdotas aparentemente simpáticas que ofrece el libro. No obstante, éstas son máscaras que ocultan la propia tristeza y el desgarramiento de un yo que busca darle sentido a la vida. Véase al respecto la sección de Permiso titulada "Verdad de las caricaturas/Verdad de las máscaras" que abre con el siguiente epígrafe de Augusto Monterroso: "El humor y la timidez generalmente se dan juntos. Tú no eres una excepción. El humor es una máscara y la timidez otra. No dejes que te quiten las dos al mismo tiempo" (211).

Detrás de estas máscaras de humor hay un hombre que se define como "quedado, dramático, fin de raza, ecléctico, escéptico sin ambiciones, condicionado por los afectos privados, dubitativo, especimen único de peruano, melancólico, nostálgico y representante del pasado" (13-23). El humor es un arma que utiliza para velar una realidad no tan feliz, pues las situaciones de desconcierto, soledad y aislamiento no escasean en su autobiografía. $\mathrm{Al}$ autor, le quedan sólo el sentido del humor y la ironía como defensa.

No obstante, la conclusión de sus memorias es que Bryce Echenique, nuevamente, como ocurría en las novelas, encuentra en el propio ejercicio literario y en las relaciones en círculos de intimidad, el afianzamiento de su identidad: "Un exilio voluntario, entonces, y 
punto, nuevamente. Pero nuevamente, también, un sin embargo. La literatura, la amistad, el amor" (Permiso 200). Finalmente acaba afirmando que la intimidad, ejemplificada por las relaciones de amistad, son el único país, es decir, la única forma de encontrar las bases de afianzamiento de su identidad:

Hace muy pocos días que recibí una carta del escritor peruano Guillermo Niño de Guzmán. Me contaba una conversación con el poeta, peruano también, Jorge Eduardo Eielson, que hablaba de la amistad como único país. Puentes fueron y puentes vinieron en ese mismo instante. Y túneles. Y ríos profundos (Permiso 203).

La autorreflexión, motivada por el desconcierto ontológico del individuo, hace que el hombre se cuestione tanto a sí mismo como a su creación. Al igual que existe una inestabilidad ontológica del individuo también existe una inestabilidad ontológica del texto (McHale 30). La forma más básica de manifestación de esta inseguridad es la manera en que la diferencia entre el mundo de la ficción y el mundo real se pone en cuestionamiento. En una poética ontológica clásica se parte del principio de que para que el mundo real se pueda reflejar miméticamente en el mundo de la ficción la imitación debe distinguirse de lo imitado. Cuando los dos planos se solapan, la ontología del texto pasa a cuestionarse, al romperse la autonomía de un texto que tenía independencia con respecto a lo imitado.

Esta inestabilidad se observa en diversas técnicas usadas por los autores contemporáneos para cuestionar el valor del texto como representación de un mundo fuera del mismo, y por último para cuestionar el propio mundo. Si el mundo está caracterizado por el desconcierto, no es extraño que ese desconcierto, que ya se reflejaba en la ontología de los personajes, se refleje también en la ontología del texto. El reflejo de esta inestabilidad ontológica del texto lo vemos ejemplificado de diversas formas en las novelas de Bryce Echenique. En Tantas veces Pedro nunca se llega a saber realmente si Sophie, que junto a Pedro Balbuena protagoniza la novela, existe realmente o es una invención del propio Pedro. El diálogo entre la presencia/ausencia de Sophie domina toda la novela: Pedro Balbuena escribe dentro de la novela historias con Sophie, habla con ella, le manda cartas, le envía telegramas mentales y les cuenta a todas las mujeres que conoce las historias de Sophie: "Hablaremos de Sophie, Virginia. No sabes cuánto te quiero" (61).

Se mantiene en interrogante a lo largo de la novela si Sophie es un ser real o producto de la imaginación de Pedro. La novela evita estas divisiones tajantes entre lo imaginado y lo real, entre lo ficcional y lo vivido. La estructura de la novela refleja la misma confusión ontológica y de percepción del protagonista. La confusión viene creada por una complicada superposición de planos ficcionales, que anulan toda suerte de certidumbre acerca de los personajes y de sus acciones dentro de la novela. Cada plano va anulando las posibilidades de veracidad del anterior. Si en uno se nos ofrece la muerte de Pedro Balbuena ¿quién es el que está contando su historia, quién es el que habla, quién es testigo de todo esto? Como resultado no se sabe si existió o no Sophie, como tampoco podemos saber si Pedro Balbuena ha sido o no el autor de la novela. La neurosis de la novela es de fondo y de forma, hasta el punto de que el propio protagonista comenta que tal y como están las cosas quizá haya que considerar la neurosis como la única certidumbre: 
En fin, la alta dosis de champán que he ingerido me permite decirte que tal como veo las cosas en el mundo hoy por hoy, la neurosis y la paranoia son los únicos comportamientos que pueden tranquilizarte un poco la conciencia. $Y$ eso ya es bastante Claudine. Pero si la cosa sigue como está, tal vez tengamos que elevar la neurosis a la categoría de ideología [...] (192).

La inestabilidad ontológica se manifiesta también en el poder del autor para ironizar sobre sus personajes y sobre sí mismo dentro de los textos. Así, el autor, para romper la autonomía de los textos, saca a los personajes del marco narrativo en el que nacieron y los presenta en otras novelas. Martín Romaña y Octavia, reaparecen en "Una carta a Martín Romaña" de la colección Magdalena peruana; hace lo mismo con Vilma, ama de Julius en la novela homónina, que reaparece en No me esperen en abril como la esposa de un profesor, con un carácter y una personalidad absolutamente dispar a la Vilma de Julius.

La ironía también se proyecta sobre sí mismo como autor cuando se presenta como personaje en La vida exagerada de Martín Romaña, El hombre que hablaba de Octavia de Cádiz y No me esperen en abril. En esta última novela el narrador lo menciona para criticar el sentimentalismo con que el autor de Un mundo para Julius recordaba la figura de Vilma en esta misma novela. El Alfredo Bryce Echenique que se presenta en La vida exagerada de Martín Romaña y El hombre que hablaba de Octavia de Cádiz es una persona contradictoria, algunas veces cordial y tímido, otras agresivo, otras ridículo. Bryce Echenique, por su parte, no se queda a la zaga y se burla abiertamente de Martín Romaña al que llamaba "Anafranilín, unas veces, y The anafranil man, otras" (La vida exagerada 441) por el nombre de la medicina que tiene que tomar para paliar su depresión neurótica. El cuestionamiento de la realidad y de la novela se refleja también en la aparición de personajes reales, con nombre y apellido, como parte de la fauna humana novelística. Si en Tantas veces Pedro aparecía Julio Ramón Ribeyro, vuelve éste a aparecer junto a Bensoussan y Saint Lu en El hombre que hablaba de Octavia de Cádiz.

Estas ironías se hicieron más comunes en la prosa de Bryce Echenique a medida que proliferaba la crítica interpretativa de sus obras. Y no sólo esto, dada la aparente similitud entre la vida de algunos personajes y la del propio escritor, se especulaba sobre la similitud entre el autor y sus personajes, y debatían lo que pertenecía a la ficción y lo que pertenecía a la vida real. Si los críticos intentaban desentrañar la psiquis de cada uno de los personajes, y también de su autor, una nueva versión de los mismos, y la aparición del propio autor como personaje contradictorio, desmentía los afanes de los críticos de buscar respuestas tajantes, y sobre todo destacaba la libertad del autor para crear y para cuestionarse él mismo su propia creación. Por otra parte estos juegos irónicos son el reflejo de la falta de certidumbres del mundo actual. El hombre por sí mismo y teniéndose a sí mismo como una única certidumbre debe ocupar el vacío que ha dejado la pérdida de las certezas en las que se basaba la tradición.

$\mathrm{Si}$ "el arte de cada época trasunta una visión del mundo y el concepto que esa época tiene de la verdadera realidad" (Sábato 31), es la obra de Alfredo Bryce Echenique un espejo en el que se proyecta nuestra propia mirada finisecular. Sus obras adquieren visos de universalidad debido a que los problemas que en ellas se plantean encuentran eco en las vicisitudes de los hombres y mujeres de este fin de siglo. Nostalgia, autorreflexión, incertidumbre, sentimentalismo, cuestionamiento de la realidad y del texto, son temas 
cruciales de estas últimas décadas del siglo XX. Alfredo Bryce Echenique ha sabido reflejar en sus obras los problemas comunes al mundo actual, de ahí el éxito que ha tenido y que ya haya quedado como testimonio de una época.

\section{Obras CITADAS}

Baudrillard, Jean. "The Ecstasy of Communication". The Post-Modern Reader. Charles Jencks, ed. Great Britain: Academy Editions, 1992. 151-158.

Blest Gana, Alberto. Los transplantados. 2 vols. París: Tip Garnier Hermanos, 1904.

Brodsky, Joseph. "The Condition We Call Exile". 1988. Renaissance and Modern Studies 34 (1991): 1-8.

Bryce Echenique, Alfredo. Un mundo para Julius. 1970. Julio Ortega, ed. Madrid: Cátedra, 1993. Tantas veces Pedro. 1977. Barcelona: Plaza y Janés, 1989. La vida exagerada de Martín Romaña. 1981. Bogotá: La Oveja Negra, 1985. El hombre que hablaba de Octavia de Cádiz. Barcelona: Plaza y Janés, 1985. Magdalena peruana y otros cuentos. Barcelona: Plaza y Janés, 1986. La última mudanza de Felipe Carrillo. 1988. México: Diana, 1990. "Los grandes hombres son así. Y también asá". Dos señoras conversan. Barcelona: Plaza y Janés, 1990. 185-287. Permiso para vivir (Antimemorias). Barcelona: Anagrama, 1993. No me esperen en abril. Barcelona: Anagrama, 1995. Reo de nocturnidad. Barcelona: Anagrama, 1997. "Alfredo Bryce Echenique: turno sentimental". Arte de innovar. Julio Ortega, ed. México: Ediciones del Equilibrista, 1994. 454-455. "La Generación del 50". Oiga. Lima, 30 de enero de 1983: 52-53.

Cornejo- Polar, Antonio. "Una heterogeneidad no dialéctica: sujeto y discurso migrantes en el Perú moderno". Revista Iberoamericana 176-177 (1996): 837-844.

Cortázar, Julio. Rayuela. 1963. Madrid: Cátedra, 1989.

Dávalos y Lisson, Ricardo. Lima de antaño. vol. I. $2^{\mathrm{a}}$ ed. Barcelona: Montaner y Simón, 1925.

"Las diez mejores novelas peruanas". Debate 17/81 (Lima, febrero-abril de 1995): 28-43. Doering, Juan Günther y Guillermo Lohmann Villena. Lima. Madrid: Mapfre, 1992. Elmore, Peter. Los muros invisibles: Lima y la modernidad en la novela del siglo XX. Lima: Mosca Azul, 1993.

Gálvez, José. Una Lima que se va. Lima: Editorial Euforion, 1921.

Giddens, Anthony. Consecuencias de la modernidad. Madrid: Alianza Editorial, 1993. Traducción de The Consequences of Modernity. California: Stanford University Press, 1990. Modernity and Self-Identity. California: Standford University Press, 1991.

González, Aníbal. "La nueva novela sentimental de Alfredo Bryce Echenique". Los mundos de Alfredo Bryce (Textos críticos). César Ferreira e Ismael P. Márquez, eds. Lima: Pontificia Universidad Católica, 1994. 203-214. 
Güiraldes, Ricardo. Raucho. Obras completas. Buenos Aires: Emecé Editores, 1962. 155235.

Gutiérrez, Miguel. "Un mundo para Julius, un fastuoso vacío". Narración 2 (julio 1971): 24 ss.

Hildebrandt, César. "Brycey el juego de las escondidas". Oiga. Lima, 22 de marzo de 1993: 52-58.

Krakusin, Margarita. La novelística de Alfredo Bryce Echenique y la tradición sentimental. Madrid: Pliegos, 1996.

Lerer, David. "El canto de cisne de un mundo". Entrevista con Alfredo Bryce Echenique. Oiga. Lima, 26 de marzo de 1972: 28-32.

Mallea, Eduardo. Nocturno europeo. 1935. Obras completas. Vol. 1. Buenos Aires: Emecé Editores, 1971: 81-144.

McCarty, Lawrence R. The Use of Humor in Three Novels of Alfredo Bryce Echenique. Tesis. Temple University, 1993.

McHale, Brian. Postmodernist Fiction. Great Britain: Methuen \& Co. Ltd, 1987.

Méndez Gastelumendi, María. Los jóvenes del nuevo Perú profundo. Lima: DESCO, 1990.

Nugent, José Guillermo. El laberinto de la choledad. Lima: Fundación Friedrich Ebert, 1992.

Quijano, Aníbal. Dependencia, urbanización y cambio social en América Latina. Lima: Mosca Azul, 1977.

Ribeyro, Julio Ramón. "Mesa redonda acerca de la Generación de los 50". José Antonio Bravo, ed. La Generación del '50: hombres de letras (Antología). Lima: Okura Editores, 1989. 179-213.

La palabra del mudo. Vol. 1. Lima: Editorial Milla Batres, 1973.

Sábato, Ernesto. El escritor y sus fantasmas. 1963. Barcelona: Seix Barral, 1997.

Salazar Bondy, Sebastián. Lima, la horrible. México: Ediciones Era, 1964. Pobre gente de Paris. Buenos Aires: Editorial Jorge Alvarez, 1965.

Solar, Alberto del. Rastaquouère (Ilusiones y desengaños sud-americanos en París). Buenos Aires: Félix Lajouane, 1890.

Weintraub, Karl Joachim. The Value of the Individual. Self and Circumstance in Autobiography. Chicago: Chicago University Press, 1978. 